\title{
Frequency of Null Phenotypes of Glutathione $S$-Transferase M1 and T1 among the Populations of Tabuk (Northwestern Part of Saudi Arabia)
}

\author{
Rashid Mir, Abdullah Yahya Hamadi, Abu-Duhier F.M.* \\ Prince Fahd Bin Sultan Research Chair, Division of Cancer Molecular Genetics, Department of Medical Lab \\ Technology,Faculty of Applied Medical Sciences, University of Tabuk, Kingdom of Saudi Arabia \\ Email: rashid@ut.edu.sa, ,fabu-duhier@ut.edu.sa
}

Received 21 November 2015; accepted 5 March 2016; published 8 March 2016

Copyright @ 2016 by authors and Scientific Research Publishing Inc. This work is licensed under the Creative Commons Attribution International License (CC BY). http://creativecommons.org/licenses/by/4.0/

(c) (i) Open Access

\section{Abstract}

Background: The variability in the distribution of the null phenotypes of GSTM1 and GSTT1, due to total or partial gene deletion resulting in the lack of the active enzyme, has been reported in different populations, especially in ethnically well-defined groups but not in Tabuk. This study investigated the variability in the distribution of the null phenotypes of GSTM1 and GSTT1 in the population of Tabuk (northwestern part of Saudi Arabia). Method: This study was conducted on 200 subjects of Tabuk-northwestern part of Saudi Arabia among which 100 were chronic smokers and 100 were nonsmokers. The subjects were reporting to hospital for routine checkup. All were without past history of any chronic disease and no significant abnormality. GST genotyping was done by multiplex PCR-based methods. The smoker and control groups were compared using a chi-square test with $P<0.05$. Results: The distribution of the GSTM1 null genotype was more frequent among non smoker individuals $(14 \%)$ than among smoker individuals $(1 \%)$ and difference was statistically significant $(P<0.0001)$ whereas the distribution of the GSTT1 null genotype showed the highest frequency among non smokers $(28 \%)$ than the smokers $(6 \%)$ and the difference was statistically significant $(P<0.003)$. GSTM1 deletion homozygosity of $14 \%$ and $1 \%$ was reported among non smokers and smokers, respectively whereas GSTT1 deletion homozygosity of $28 \%$ and $6 \%$ was reported among non smokers and smokers, respectively. Our results indicate that there are major differences in allelic distribution of GSTM1 and GSTT1 genes between the two groups investigated. Combined analysis of both genes revealed that $15 \%$ of smokers and non smokers harbor the deleted genotype of GSTM1 and 34\% of smokers and non smokers harbor the deleted genotype of GSTT1 with significant differences. Conclusion: This study enables selecting subgroups among the general population who are more susceptible to DNA damage and will help

\footnotetext{
"Corresponding author.
}

How to cite this paper: Mir, R., Hamadi, A.Y. and Abu-Duhier, F.M. (2016) Frequency of Null Phenotypes of Glutathione S-Transferase M1 and T1 among the Populations of Tabuk (Northwestern Part of Saudi Arabia). Open Journal of Genetics, 6, 9-18. http://dx.doi.org/10.4236/ojgen.2016.61002 
genetic studies on the association of GST polymorphisms with disease risks and drug effects in Arab population. Studies with a larger sample size are needed to evaluate and confirm the validity of our results.

\section{Keywords}

\section{GSTT1-Mu Glutathione S-Transferase, GSTT1-Theta Glutathione S-Transferase, Null Phenotypes of GST, Tabuk-A Northwestern Part of Saudi Arabia}

\section{Introduction}

GST family genes have a critical role in xenobiotic metabolism and drug resistance and have a major role in the carcinogen detoxification process. GSTs play a critical role by protecting against the ROS caused by the breakdown of the peroxidased lipids and they are capable of oxidizing DNA and generating damage [1]. GSTs are involved in phase II metabolism, catalyzing the conjugation of soluble glutathione with reactive intermediates produced during the bioactivation of procarcinogens and detoxification of carcinogens [2]. The seven distinct classes of soluble GST that are highly expressed in the mammalian liver are comprised of alpha, mu, pi, theta, kappa, sigma, zeta and omega gene families [3]. Of these classes of GSTs, five (GSTM1, GSTM3, GSTT1, GSTP1 and GSTZ1) have been shown to be polymorphologically distributed [4]. The functional polymorphisms of GST pi (GSTP1), GST mu (GSTM1) and GST theta (GSTT1) in GSTs genes have been shown to be associated with catalytic activity of enzymes and scavenging capacity of ROS [5]. GSTT1 is represented by two alleles: a functional or wild allele (GSTT1*1), and a nonfunctional or null allele (GSTT1*0). Studies have shown that the GSTT $1 * 0$ allele corresponds to total or partial deletion of the gene, causing a deficiency in its enzymatic activity [6]. Defects in detoxifying ROS may influence the development and the severity of diseases related to ROS [7].

A number of studies done so far in different populations have shown that polymorphisms within the GST genes play an important role in determining individual susceptibility to cancer; however, data obtained so far have been contradictory within the same or different populations. Molecular epidemiological studies have provided three pieces of information about the relationship of GSTM1 and GSTT1 with cancer susceptibility. First, the frequencies of homozygous GSTM1 and GSTT1 deletion carriers are very high (i.e., 20\% - 50\%) in most populations studied to date. Second, GSTM1 and, possibly, GSTT1 may be involved in the etiology of cancer at more than one site. Third, the risk conferred to individuals who carry homozygous deletions in GSTM1 and GSTT1 appears to be small in magnitude (e.g., odds ratio of <2). However, the magnitude of risk is larger (e.g., odds ratio of 3 - 5) when interactions of GSTM1 of GSTT1 with other factors (e.g., cigarette smoking) are considered. These findings have implications for studies of GSTM1 and GSTT1 in cancer susceptibility and for future applications of these biomarkers in cancer prevention of control strategies [8].

Several epidemiological studies suggest that individuals who are homozygous null at the GSTM1 and GSTT1 loci (i.e., lack both copies of the GSTM1 and/or GSTT1 variants of the GST gene family) have an increased risk of developing various types of neoplastic diseases, including cancers of the bladder, prostate, colon, skin, lung, head and neck and stomach [9]-[12]. The varied distribution of GSTM1 and GSTT1 null genotypes was reported in different populations [13]-[15]. The GSTM1 null genotype frequencies vary from 38\% - 67\% in Europeans, $33 \%-63 \%$ in Asians, and 16\% - 36\% in sub-Saharan Africans, Bahraini (49.7\%), Lebanese (52.5\%), and Austrians (49\%). Approximately half of the Caucasian populations are homozygous deleted for GSTM1 null allele, and hence fail to express the enzyme. Given that gene polymorphism may predispose these populations to certain adverse drug reactions or disease occurrence, here we analyzed the frequency of GSTM1 and GSTT1 polymorphisms in Tabuk (northwestern of Saudi Arabia) populations.

\section{Materials and Methods}

The study was conducted in the Division of Cancer Molecular Genetics, Prince Fahd Bin Sultan Research chair, University of Tabuk, Saudi Arabia. 


\subsection{Selection Criteria}

This study included 100 healthy individuals (smokers) and 100 nonsmokers of TABUK-northwestern Saudi Arabia. The subjects were reporting to hospital for routine checkup.

\subsection{Data Collection}

All the Subjects were interviewed using a structured questionnaire regarding epidemiological/demographic data, past history, history of addiction particularly smoking, family history of any significant diseases.

\subsection{DNA Extraction and GST Genotyping}

Venous blood was collected in EDTA tubes from all subjects and controls and the high molecular genomic DNA was isolated using DNA extraction QIAamp DNA Blood Mini Kit (51106) and samples were stored at $-20^{\circ} \mathrm{C}$ until PCR. The ratio of absorbance at $260 \mathrm{~nm}$ and $280 \mathrm{~nm}$ was used to assess the purity of DNA by Thermo Scientific NanoDrop ${ }^{\mathrm{TM}}$. A ratio of $\sim 1.8$ to 1.95 was generally obtained.

\subsection{Multiplex PCR for GST Genotyping}

Briefly, 50 ng of DNA was amplified in a $25 \mu 1$ multiplex reaction mixture containing 25 pmol of each of the following primers as depicted in Table 1 and $12.5 \mu$ from TGoTaq ${ }^{\circledR}$ Green Master Mix (cat no M7122) (Promega, USA) which is composed of GoTaq ${ }^{\circledR}$ DNA Polymerase, 2X Green GoTaq ${ }^{\circledR}$ Reaction Buffer (pH 8.5), 400 $\mu \mathrm{M}$ dATP, $400 \mu \mathrm{M}$ dGTP, $400 \mu \mathrm{M} \mathrm{dCTP}, 400 \mu \mathrm{M}$ dTTP and $3 \mathrm{mM} \mathrm{MgCl}_{2}$. The buffer contains yellow and blue dyes, which function as loading dyes when reaction products are analyzed by agarose gel electrophoresis which prevents the use of toxic Et-Br. The multiplex PCR method was used to detect the presence or absence of the GSTT1 and GSTM1 genes in the genomic DNA samples, simultaneously in the same tube. Each set of reaction included both positive and negative controls. The reaction mixture was subjected to initial denaturation at $94^{\circ} \mathrm{C}$ for $1 \mathrm{~min}$, followed by 35 cycles of $94^{\circ} \mathrm{C}$ for 58 seconds, $59^{\circ} \mathrm{C}$ for 58 seconds, and $72^{\circ} \mathrm{C}$ for 58 seconds. The final extension was done at $72^{\circ} \mathrm{C}$ for $10 \mathrm{~min}$. The amplification products were separated by electrophoresis through 1\% agarose gel stained with ethidium bromide. Length of PCR products from positive for GSTM1 and GSTT1 genotypes yielded bands of 215bp and 480bp respectively while the internal positive control (CYP1A1) PCR product corresponded to 312 bp as depicted in the as depicted in Figure 1. The subjects were classified as either positive (when at least one copy of the gene was present) or null genotypes. Heterozygous and homozygous individuals for GSTM1 (GSTM1 +/0 and GSTM1 +/+) or GSTT1 (GSTT1 +/0 and GSTT1 +/+) have been reported to present similar enzyme expression levels and were considered together for statistical analysis.

\subsection{Statistical Analysis}

The distribution of the GSTM1 and GSTT1 genotypes was evaluated for Hardy-Weinberg equilibrium using chi-squared analysis, as described. Chi Square test or Fisher Exact Probability test was used for analysis of frequency distribution of subjects in various subgroups. Odds ratio and confidence interval were used to estimate risk of contracting disease in presence of various risk factors. Statistical significance was accepted as $\mathrm{P}<0.05$ (Two tailed). All analyses were done using EPI 6 software (Epi info 6 CDC).

\section{Table 1. Primer sequence for GST genotyping.}

\begin{tabular}{|c|c|c|c|}
\hline Gene & Primer sequence & Annealing tempt & PCR products \\
\hline \multirow[t]{2}{*}{ GSTM1 } & F-5'-GAACTCCCTGAAAA GCTAAAGC-3' & $58^{\circ} \mathrm{C}$ & 215 bp \\
\hline & R-5’-GTTGGGCTCAAATA TACGGTGG-3’ & & \\
\hline \multirow[t]{2}{*}{ GSTT1 } & F-5’-TTCСТTACTGGTCCT САСАTCTC-3’ & & 480 bp \\
\hline & R-5'-TCACGGGATCATGGCC AGCA-3' & & \\
\hline \multirow[t]{2}{*}{ CYP1A1 } & F-5'-GAACTGCCACTTCAGCTGTCT-3' & & 312 bp \\
\hline & R-5'-CAGCTGCATTTGGAAGTGCTC-3' & & \\
\hline
\end{tabular}




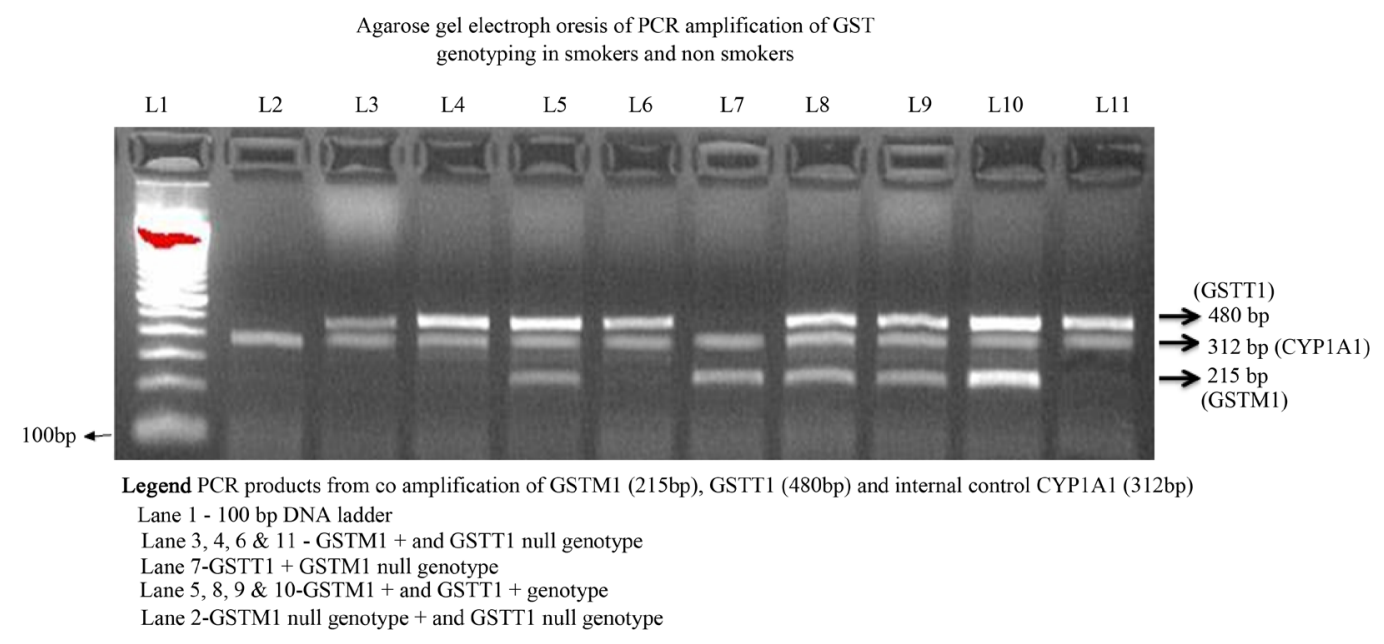

Figure 1. Agarose gel electrophoresis of PCR amplification of GST genotyping.

\section{Results}

GSTM1 and GSTT1 genotyping were assessed by multiplex PCR in 100 smoker individuals and 100 non smoker individuals of Tabuk a Northwestern part of Saudi Arabia). While this method does not differentiate between wild-type and heterozygous states, it determines the percentages of the homozygous deletion of both GSTM1 and GSTT1 genes. GST genotypes were coded as positive (wild-type homozygotes and deletion heterozygotes), or as null (homozygous deletion). This made direct calculation of Hardy Weinberg Equilibrium impossible.

\subsection{Frequency of the GSTM1/T1 Genotype among the Study Population}

The distribution of the GSTM1 null genotype was more frequent among non smoker individuals (14\%) than among smoker individuals (1\%) as depicted in Table 1 and Figure 1. Similarly the distribution of the GST T1 null genotype was more frequent among non smoker individuals (14\%) than among smoker individuals (1\%) as depicted in Table 2 and Figure 2 \& Figure 3.

\subsection{Correlation of GSTM1 Null Genotype between Smokers \& Non Smoker}

The significant correlation was reported between non smoker individuals and smoker individuals. The difference was statistically significant $(\mathrm{P}<0.0003)$ as depicted in the Table 3.

\subsection{Correlation of GSTT1 Null Genotype between Smokers \& Non Smoker}

The significant correlation was reported between non smoker individuals and smoker individuals as depicted in Table 1 . The difference was statistically significant $(\mathrm{P}<0.0001)$ as depicted in the Table 4 .

\subsection{Allele Frequencies of GSTT1 among Study Population}

The allele frequencies of GSTT1 (normal) and (null) genotypes in according to Chi-sq Hardy-Weinberg equilibrium test calculator for biallelic markers as depicted in Table 5 .

\subsection{Allele Frequencies of GSTM1 among Study Population}

The allele frequencies of GSTM1 (normal) and (null) genotypes in according to Chi-sq Hardy-Weinberg equilibrium test calculator for biallelic markers as depicted in Table 6 .

\subsection{Correlation between Tobacco-Users and Non-Users with GSTM1 and GSTT1 Genotypes}

The "worst" detoxifier genotype (the combined genotype of GSTM1 null and GSTT1 null) was found in 14 of 


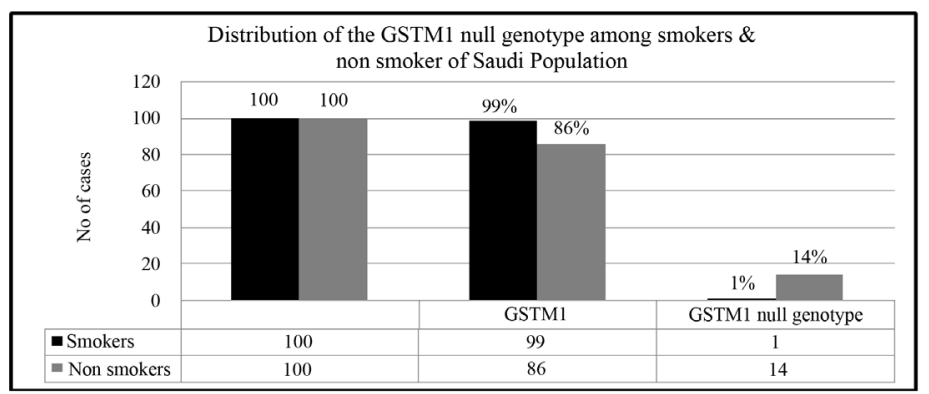

Figure 2. Distribution of GSTM1 genotypes among the study population.

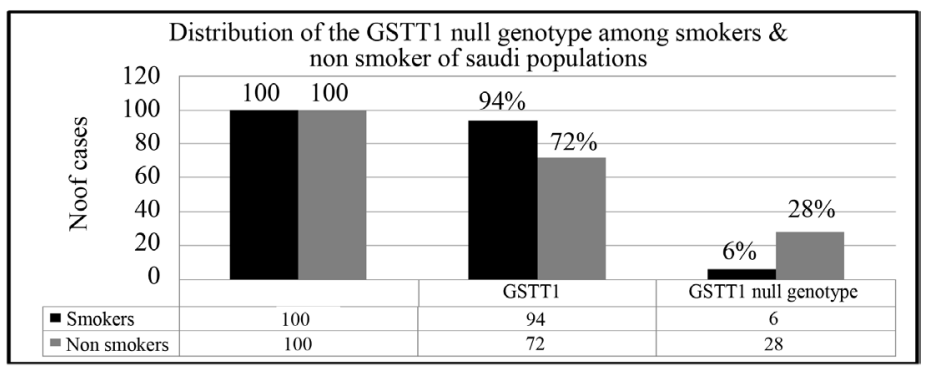

Figure 3. Distribution of GSTT1 genotypes among the study population.

Table 2. Frequencies of the genotypes of the GSTM1 and GSTT1 polymorphisms.

\begin{tabular}{cccccc} 
Group & N & $\begin{array}{c}\text { GSTM1 } \\
\text { normal genotype }\end{array}$ & $\begin{array}{c}\text { GSTM1 } \\
\text { null genotype }\end{array}$ & $\begin{array}{c}\text { GSTT1 } \\
\text { normal genotype }\end{array}$ & $\begin{array}{c}\text { GSTT1 } \\
\text { null genotype }\end{array}$ \\
\hline Smokers & 100 & $99(99 \%)$ & $01(1 \%)$ & $94(94 \%)$ & $6(6 \%)$ \\
Non smokers & 100 & $86(86 \%)$ & $14(14 \%)$ & $72(72 \%)$ & $28(28 \%)$ \\
\hline
\end{tabular}

Table 3. Association of GSTM1 null genotype between smokers \& non smoker.

\begin{tabular}{|c|c|c|c|c|}
\hline Group & $\begin{array}{c}\text { GSTM1 } \\
\text { normal genotype }\end{array}$ & $\begin{array}{c}\text { GSTM1 } \\
\text { null genotype }\end{array}$ & Chi-square & $P$ value \\
\hline Smokers & 99 & 01 & 10.38 & $<0.0013$ \\
\hline Non smokers & 86 & 14 & & \\
\hline
\end{tabular}

GST = glutathione S-transferase; GSTM1 = GST mu; ${ }^{*} \mathrm{P}<0.05$ compared between smokers and non smokers (Fisher exact test).

Table 4. Association of GST T1 null genotype between smokers \& non smoker.

\begin{tabular}{ccccc}
\hline Group & $\begin{array}{c}\text { GSTT1 } \\
\text { normal genotype }\end{array}$ & $\begin{array}{c}\text { GSTT1 } \\
\text { null genotype }\end{array}$ & Chi-square & P value \\
\hline Smokers & 94 & 6 & 15.63 \\
Non smokers & 72 & 28 & $<.0001$ \\
\hline
\end{tabular}

GST = glutathione S-transferase; GSTT1 = GST theta. ${ }^{*} \mathrm{P}<0.05$ compared between smokers and non smokers (Fisher exact test).

Table 5. Allele frequencies of GSTT1 genotypes among study population.

\begin{tabular}{ccccc}
\hline Group & $\begin{array}{c}\text { GSTT1 } \\
\text { normal genotype }\end{array}$ & $\begin{array}{c}\text { GSTT1 } \\
\text { null genotype }\end{array}$ & $\begin{array}{c}\text { GSTT1 } \\
\text { Allele freq }\end{array}$ & $\begin{array}{c}\text { GSTT1 } \\
\text { null freq }\end{array}$ \\
Smokers & 94 & 6 & 0.94 & 0.06 \\
Non smokers & 72 & 28 & 0.72 \\
\hline
\end{tabular}

Table 6. Allele frequencies of GSTM1 genotypes among study population.

\begin{tabular}{ccccc}
\hline Group & $\begin{array}{c}\text { GSTM1 } \\
\text { normal genotype }\end{array}$ & $\begin{array}{c}\text { GSTM1 } \\
\text { null genotype }\end{array}$ & $\begin{array}{c}\text { GST M1 } \\
\text { Allele freq }\end{array}$ & $\begin{array}{c}\text { GST M1 } \\
\text { null freq }\end{array}$ \\
\hline Smokers & 99 & 01 & 0.99 & 0.01 \\
Non smokers & 86 & 14 & 0.14 & 0.14 \\
\hline
\end{tabular}


100 (GSTM1) and 28/100 (GSTT1) northwestern Saudi Arabia female populations and 1 of 100 (GSTM1) and 14/100 (GSTT1) northwestern Saudi Arabia male populations. The difference was statistically significant as depicted Table 7. The OR of "worst” detoxifier genotype versus all other genotypes was $2.72(95 \%$ CI = $1.00-$ 13.45).

\section{Discussion}

This is the first study to evaluate the prevalence of the GSTT1 and GSTM1 gene polymorphisms in Tabuk Region (Northwestern Saudi Arabia), because no data are available for this region. This study provided us with an excellent opportunity to explore the frequency of GSTM1 and GSTT1 null genotypes, gene-gene and genotypecigarette smoking interactions.

\subsection{Smoking-Related to Glutathione S-Transferases (GST)}

Tobacco smoke is a major cause of many diseases. Although its carcinogenic role via induction of DNA damage and mutation is well established, GSTM1-null was reported to be associated in some studies with increased susceptibility to inflammatory pathologies and increased risk of smoking-related cancers [16]. GST is a family of enzymes that detoxify reactive electrophiles, particularly present in tobacco smoke, reactive oxygen species, and known or suspected carcinogenic compounds Modulation of DNA damage and mutation caused by polymorphisms in detoxification enzymes, including the glutathione $S$-transferases (GSTs), is a well-established risk factor for tobacco-related carcinogenesis, and a similar change in cellular damage may be involved in the risk of disease associated with tobacco smoking [17]. Of four classes of GST isoenzymes, null genotypes of GSTM1 which belongs to the $\mu$ class and of GSTT1 which is in the class are associated with increased risk of smokingrelated cancer [18]. The free radical scavenging enzymes, GSTT1 and GSTM1, have an important role in detoxifying systems due to their ability to convert the carcinogenic compounds to excretable metabolites. There is evidence that GSTs are candidate genes on cancer susceptibility. As GST enzymes malfunction in the case of GST homozygous null polymorphism, the risk of cancer may increase in an individual who have GSTs null polymorphisms [19]. GSTT1 gene on chromosome 22q11,2 has two classes denoted as GSTT1-null homozygote for the null allele (GSTT1-0), and GSTT1-1 with at least one functional allele. The GSTT1 enzyme encoded by GSTT1-1 catalyzes the detoxification of monohalomethanes and ethylene oxide, present in cigarette smoke [20], and deficiency of its activity is associated with high risk of smoking-related cancers [21].

Tobacco smoking is a strong risk factor in the development of cancers. Tobacco is consumed both in smoking and smokeless forms. Tobacco smoke comprises nearly 60 carcinogenic compounds whereas its unburned form contains 16 identified carcinogens [22]. Among these, 4-(methylnitrosamino)-1-(3-pyridyl)-1-butanone (NNK) and polycyclic aromatic hydrocarbons (PAH) are considered to be the most important causative agents for the development of lung cancer. PAH require metabolic activation and subsequent binding to DNA (forming bulky "PAH-DNA adducts") to exert their carcinogenic action [23]. Similar activation of one of the N-nitrosamines, NNK, by the P450 system produces metabolites that form methyl and pyridyloxobutyl DNA adducts. Detoxification of these toxic metabolites occurs via the action of multiple Phase II enzymes, most notably the glutathione-S-transferases. There are many studies in the literature that analyze the effects of GSTT1 and GSTM1

Table 7. Association between tobacco-users and non-users with GSTM1 and GSTT1 genotypes.

\begin{tabular}{|c|c|c|c|c|c|c|c|}
\hline Group & $\mathbf{N}$ & Smokers & Non smokers & $\mathrm{OR}^{*}(95 \% \mathrm{CI})$ & $\mathbf{R R}^{\#}(\mathbf{9 5 \%} \mathbf{C I})$ & $\mathrm{RD}^{\wedge}(95 \% \mathrm{CI})$ & $P$ value \\
\hline $\begin{array}{c}\text { GSTT1 } \\
\text { normal genotype }\end{array}$ & 100 & 94 (94\%) & 72 (72\%) & 1.00 & 1.00 & & \\
\hline $\begin{array}{c}\text { GSTT1 } \\
\text { null genotype }\end{array}$ & & $6(6 \%)$ & 28 (28\%) & $\begin{array}{c}5.2 \\
(2.03-13.45)\end{array}$ & $\begin{array}{c}2.8 \\
(1.37-5.86)\end{array}$ & $\begin{array}{c}36.6 \\
(20.45-52.80)\end{array}$ & $<0.0005$ \\
\hline $\begin{array}{c}\text { GSTM1 } \\
\text { normal genotype }\end{array}$ & 100 & 99 (99\%) & 86 (86\%) & 1.00 & 1.00 & & \\
\hline $\begin{array}{c}\text { GSTM1 } \\
\text { null genotype }\end{array}$ & & 01 (1\%) & 14 (14\%) & $\begin{array}{c}16.1 \\
(2.08-125.1)\end{array}$ & $\begin{array}{c}8.0 \\
(1.2-53.58)\end{array}$ & $\begin{array}{c}46.8 \\
(32.3-61.37)\end{array}$ & $<0.0013$ \\
\hline
\end{tabular}

*OR: Odd ratio ${ }^{\#}$ RR: Risk ratio ${ }^{\wedge}$ RD: Risk difference. 
polymorphisms on the risk of developing different disease. When the findings of them are examined in detail, it can be seen that different results exist. As the GSTs are important in the detoxification of toxic molecules in tobacco, their variant genotypes should be investigated together in susceptibility to cancer.

The underlying reasons of these differences were the sample size of study, ethnic differences, the smoking habits (heavy/mild/light smoker), the type of endogenous and exogenous genotoxicants and exposure time to them as well as genetic structures of enzymes having role for the detoxification. The genetic structure (in terms of mutation and polymorphisms) of other enzymes having a role for the detoxification, diet and the exposure time to the endogenous and exogenous genotoxicants may affect the age of onset and type of cancer among different populations.

\subsection{Distribution of GSTM1 and GSTT1 Null Genotypes in Different Populations}

The frequency of the GSTM1 null genotype was more frequent among non-smoker individuals (14\%) than the smoker individuals (1\%). Similarly the higher frequency of GSTT1 null genotype was reported among nonsmokers (Females) (28\%) than the smokers (6\%). While the distribution of GSTM1 and GSTT1 null genotypes were described previously for different population as depicted in the Figure 4 and Table 8 but no data has been published from Tabuk Region of northwestern Saudi Arabia.

We investigated the polymorphism at GST loci in the populations of Tabuk Region in northwestern Saudi Arabia. The frequency of the GSTT1 null genotype in the present study was significantly higher than those in the populations of North Indian, South India, England, Turkish-USA, Brazil, Italy, Caucasians and Africa whereas the frequency of null genotype in the present study was significantly lower than those in Japan and China as depicted in the Table 8. The frequency of the GSTM1 null genotype in the present study was significantly lower than those in the populations of rest of the world except Gambia.

Comparing the frequencies of GSTM1 deletion in our study with other studies, we found homozygosity generally comparable with Gambia. Similarly comparing the frequencies of GSTT1 deletion in our study with other studies, we found homozygosity generally comparable with Tunisians (37\%) Bahraini (29\%) and Lebanese

Table 8. Distribution of GSTM1 and GSTT1 null genotypes in different populations of the world.

\begin{tabular}{|c|c|c|c|c|}
\hline Country/region & GSTM1 & GSTM1 null & GSTT1 null & References \\
\hline Tabuk (Northwestern Saudi Arabia) & 100 & $15 \%$ & $34 \%$ & Our study \\
\hline Lebanese & 141 & $52.5 \%$ & $37.6 \%$ & [24] \\
\hline Tunisians & 186 & $63.3 \%$ & $37.1 \%$ & [25] \\
\hline Bahrainis & 167 & $49.7 \%$ & $28.7 \%$ & [24] \\
\hline North India & 248 & $33 \%$ & $18.4 \%$ & [26] \\
\hline England & 88 & $50.8 \%$ & $16.9 \%$ & [27] \\
\hline Central Europe & 70 & $45 \%$ & $13 \%$ & [28] \\
\hline Turkish & 64 & $51.9 \%$ & $16.3 \%$ & [29] \\
\hline Japan & 39 & $55.7 \%$ & $44.3 \%$ & [30] \\
\hline W-USA & 188 & $52 \%$ & $16 \%$ & [31] \\
\hline Chinese & 234 & $51 \%$ & $46 \%$ & [32] \\
\hline Brazilian Non White & 179 & $34.2 \%$ & $25.7 \%$ & [33] \\
\hline Italians & 145 & $46.9 \%$ & $19 \%$ & [34] \\
\hline Caucasian & 85 & $48.8 \%$ & $19.9 \%$ & [35] \\
\hline South India & 361 & $30.1 \%$ & $16.8 \%$ & [36] \\
\hline Egypt & 89 & $55.5 \%$ & $29.5 \%$ & [37] \\
\hline African-American & 195 & $28 \%$ & $17 \%$ & [38] \\
\hline Gambia & 269 & $20.2 \%$ & $37.1 \%$ & [39] \\
\hline
\end{tabular}




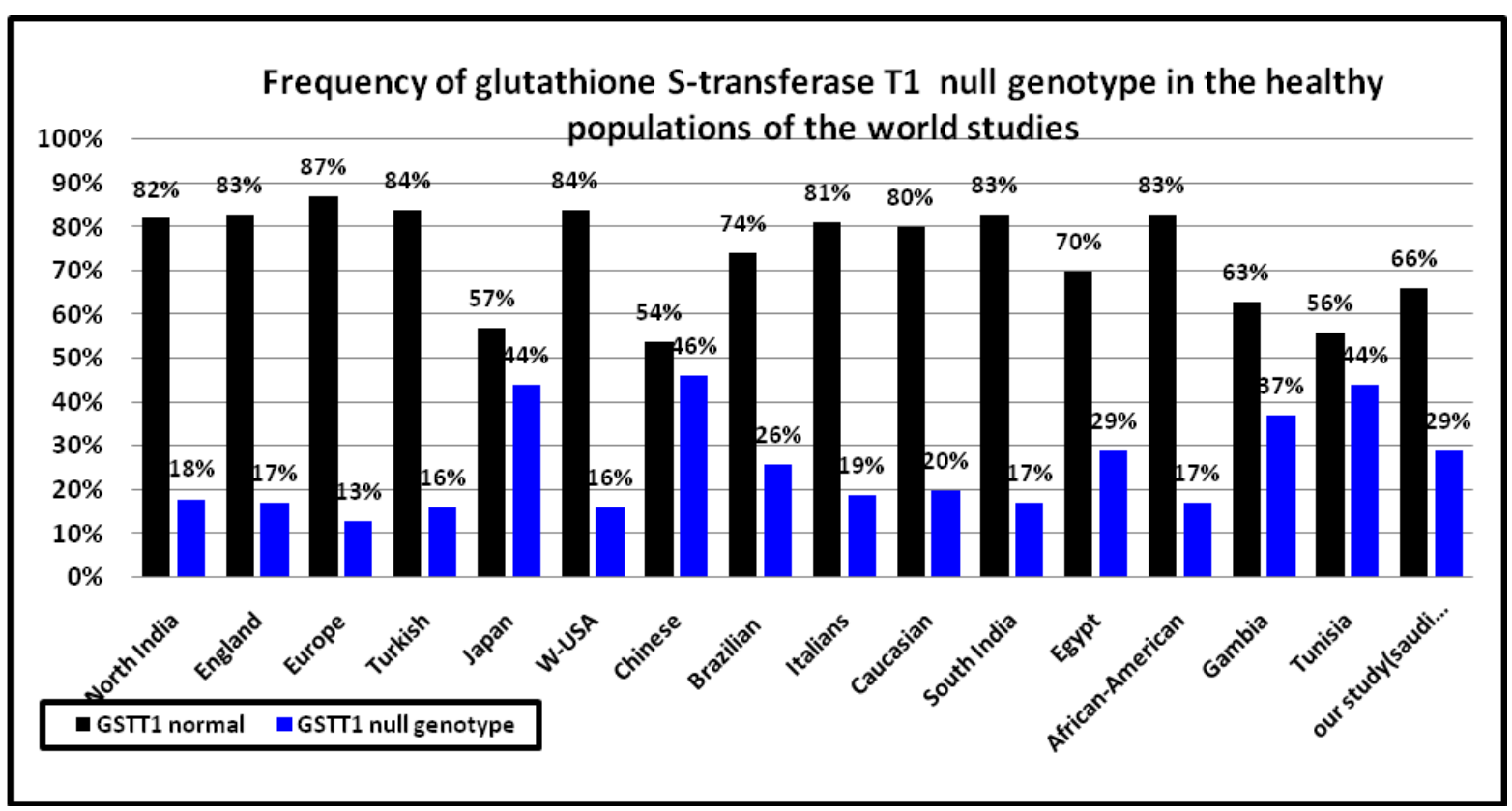

Figure 4. Frequency of glutathione S-transferase T1 null genotype in the healthy populations of the world studies.

(37\%) and Egypt (29\%). Statistically significant differences were detected when we compared smokers and non smokers $(\mathrm{P}<0.001)$, which may be due to gender and ethnic mixture in this population. The homozygosity for the GSTT1 deletion in the four populations Tunisian (37\%) Bahraini (29\%) and Lebanese (37\%) and Egypt (29\%) were comparable to those reported for Tabuk population of Saudi Arabia. GSTM1 null genotype are not uniformly distributed among diverse population, but an ethnic and geographic basis of distribution was suggested.

There are wide variations in the frequencies of GSTT1 deletion (GSTT1*0/0) among different ethnicities. Human phenotyping is facilitated by the GST activity towards methyl bromide or ethylene oxide in erythrocytes which is representative of the metabolic GSTT1 competence of the entire organism. Inter-individual variations in xenobiotic metabolism capacities may be due to polymorphisms of the genes coding for the enzymes themselves or of the genes coding for the receptors or transcription factors which regulate the expression of the enzymes.

The polymorphisms in several regions of genes may cause altered ligand affinity, transactivation activity or expression levels of the receptor subsequently influencing the expression of the downstream target genes. Studies of individual susceptibility to toxicants and gene-environment interaction are now emerging as an important component of molecular epidemiology.

Nevertheless the activity of these enzymes may differ due to polymorphisms which ultimately results in interindividual susceptibility to cancer development. Our results provided useful information in selecting target SNPs that are likely to have an impact on GST activity and contribute to an individual's susceptibility to the disease. Furthermore, protective effect of GSTT1 was strongly associated with smokers only. It is suggested that GSTM1 and GSTT1 genotypes do not individually influence susceptibility to develop disease.

\section{Conclusion}

This is the first study that addresses GST gene polymorphism among the populations of Tabuk (northwestern part of Saudi Arabia) and will help genetic studies on the association of GSTM1 and GSTT1 polymorphisms with disease risks and drug effects in Arab population. However, further studies with a larger sample size are needed to provide more precise evidence.

\section{Acknowledgements}

We acknowledge the support of Dr. Fawzia Sharaf for providing Non smoker subjects and Dr. Jamsheed Javid 
for his technical support.

\section{Competing Interests}

The authors declare that they have no competing interests.

\section{References}

[1] Singh, M.S. and Michael, M. (2009) Role of Xenobiotic Metabolic Enzymes in Cancer Epidemiology. Methods in Molecular Biology, 472, 243-264. http://dx.doi.org/10.1007/978-1-60327-492-0_10

[2] Board, P.G. and Menon, D. (2013) Glutathione Transferases, Regulators of Cellular Metabolism and Physiology. Biochimica et Biophysica Acta, 830, 3267-3288. http://dx.doi.org/10.1016/j.bbagen.2012.11.019

[3] Hayes, J.D., Flanagan, J.U. and Jowsey, I.R. (2005) Glutathione Transferases. Annual Review of Pharmacology and Toxicology, 45, 51-88. http://dx.doi.org/10.1146/annurev.pharmtox.45.120403.095857

[4] Board, P., Coggan, M., Johnston, P., Ross, V., Suzuki, T. and Webb, G. (1990) Genetic Heterogeneity of the Human Glutathione Transferases: A Complex of Gene Families. Pharmacology \& Therapeutics, 48, 357-369. http://dx.doi.org/10.1016/0163-7258(90)90054-6

[5] Pemble, S., Schroeder, K.R., Spencer, S.R., Meyer, D.J., Hallier, E., Bolt, H.M., Ketterer, B. and Taylor, J.B. (1994) Human Glutathione S-Transferase Theta (GSTT1): cDNA Cloning and the Characterization of a Genetic Polymorphism. Biochemical Journal, 300, 271-276. http://dx.doi.org/10.1042/bj3000271

[6] Gattás, G.J.F., Kato, M., Soares-Vieira, J.A., Siraque, M.S., Koher, P., Gomes, L., Rego, M.A.V. and Bydlowske, S.P. (2004) Ethnicity and Glutathione S-Transferase (GSTM1/GSTT1) Polymorphisms in a Brazilian Population. Brazilian Journal of Medical and Biological Research, 37, 451-458. http://dx.doi.org/10.1590/S0100-879X2004000400002

[7] Harries, L.W., Stubbins, M.J., Forman, D., Howard, G.C. and Wolf, C.R. (1997) Identification of Genetic Polymorphisms at the Glutathione S-Transferase Pi Locus and Association with Susceptibility to Bladder, Testicular and Prostate Cancer. Carcinogenesis, 18, 641-644. http://dx.doi.org/10.1093/carcin/18.4.641

[8] Rebbeck, T.R. (1997) Molecular Epidemiology of the Human Glutathione S-Transferase Genotypes GSTM1 and GSTT1 in Cancer Susceptibility. Cancer Epidemiology Biomarkers \& Prevention, 6, 733-743.

[9] Garte, S., Gaspari, L., Alexandrie, A.K., et al. (2001) Metabolic Gene Polymorphism Frequencies in Control Populations. Cancer Epidemiology Biomarkers \& Prevention, 10, 1239-1248.

[10] Engel, L.S., Taioli, E., Pfeiffer, R., et al. (2002) Pooled Analysis and Meta-Analysis of Glutathione S-Transferase M1 and Bladder Cancer: A HuGE Review. American Journal of Epidemiology, 156, 95-109. http://dx.doi.org/10.1093/aje/kwf018

[11] Geisler, A.S. and Olshan, A.F. (2001) GSTM1, GSTT1, and the Risk of Squamous Cell Carcinoma of the Head and Neck: A Mini-HuGE Review. American Journal of Epidemiology, 154, 95-105. http://dx.doi.org/10.1093/aje/154.2.95

[12] Reszka, E. and Wasowicz, W. (2001) Significance of Genetic Polymorphisms in Glutathione S-Transferase Multigene Family and Lung Cancer Risk. International Journal of Occupational Medicine and Environmental Health, 14, 99-113.

[13] Knudsen, L.A., Loft, S.H. and Autrup, H. (2001) Risk Assessment: The Importance of Genetic Polymorphisms in Man. Mutation Research, 483, 83-88. http://dx.doi.org/10.1016/S0027-5107(01)00213-5

[14] Cotton, S.C., Sharp, L., Little, J. and Brockton, N. (2000) Glutathione S-Transferase Polymorphisms and Colorectal Cancer: A HuGE Review. American Journal of Epidemiology, 151, 7-32. http://dx.doi.org/10.1093/oxfordjournals.aje.a010124

[15] Roy, B., Majumder, P.P., Dey, B., Chakraborty, M., Banerjee, S., Roy, M., Mukherjee, N. and Sil, S.K. (2001) Ethnic Differences in Distributions of GSTM1 and GSTT1 Homozygous “Null” Genotypes in India. Human Biology, 73, 443450. http://dx.doi.org/10.1353/hub.2001.0040

[16] Bell, D.A., Taylor, J.A., Paulson, D.F., Robertson, C.N., Mohler, J.L. and Lucier, G.W. (1993) Genetic Risk and Carcinogen Exposure: A Common Inherited Defect of the Carcinogen-Metabolism Gene Glutathione S-Transferase M1(GSTM1) that Increases Susceptibility to Bladder Cancer. Journal of the National Cancer Institute, 85, 1159-1164. http://dx.doi.org/10.1093/jnci/85.14.1159

[17] Wilson, W.H., Grant, P.J., Kain, K., Warner, D.P. and Wild, C.P. (2003) Association between the Risk of Coronary Artery Disease in South Asians and a Deletion Polymorphism in Glutathione S-Transferase M1. Biomarkers, 8, 43-50. http://dx.doi.org/10.1080/1354750021000042439

[18] Strange, R.C. and Fryer, A.A. (1999) The Glutathione S-Transferases: Influence of Polymorphism on Cancer Susceptibility. IARC Scientific Publications, 148, 231-249.

[19] Sreeja, L., Syamala, V., Hariharan, S., Madhavan, J., Devan, S.C. and Ankathil, R. (2005) Possible Risk Modification 
by CYP1A1, GSTM1 and GSTT1 Gene Polymorphisms in Lung Cancer Susceptibility in a South Indian Population. Journal of Human Genetics, 50, 618-627. http://dx.doi.org/10.1007/s10038-005-0303-3

[20] Their, R., Brüning, T., Roos, P.H., Rihs, H.P., Golka, K., Ko, Y. and Bolt, H.M. (2003) Markers of Genetic Susceptibility in Human Environmental Hygiene and Toxicology: The Role of Selected CYP, NAT and GST Genes. International Journal of Hygiene and Environmental Health, 206, 149-171. http://dx.doi.org/10.1078/1438-4639-00209

[21] Brockmoller, J., Cascorbi, I., Kerb, R. and Roots, I. (1996) Combined Analysis of Inherited Polymorphisms in Arylamine N-Acetyltransferse 2, Glutathione S-Transferases M1 and T1, Microsomal Epoxide Hydrolase, and Cytochrome P450 Enzymes as Modulators of Bladder Cancer Risk. Cancer Research, 56, 3915-3925.

[22] Hecht, S.S. (2003) Tobacco Carcinogens, Their Biomarkers and Tobacco-Induced Cancer. Nature Reviews Cancer, 3, 733-744. http://dx.doi.org/10.1038/nrc1190

[23] Poulsen, M.T. and Loew, G.H. (1981) Quantum Chemical Studies of Methyl and Fluoro Analogs of Chrysene: Metabolic Activation and Correlation with Carcinogenic Activity. Cancer Biochemistry Biophysics, 5, 81-90.

[24] Salem, A.H., Yaqoob, A., Ali, M., Handu, S., Fadel, R., Abu-Hijleh, M. and Almawi, W. (2011) Genetic Polymorphism of the Glutathione S-Transferase M1 and T1 Genes in Three Distinct Arab Populations. Disease Markers, 31, 311-316.

[25] Gara, S., Abessi, M., Bendjemena, K., Abdennebi, M. and Guemira, F. (2010) Deletion Polymorphism of Glutathione S-Transferases M1 and T1 in the Tunisian Population. La Tunisie Medicale, 88, 700-702.

[26] Mishara, D.K., et al. (2004) Allelic Variation of GSTT1, GSTM1 and GSTP1 Genes in North Indian Population. Asian Pacific Journal of Cancer Prevention, 5, 362-365.

[27] Welfare, M., Adeokun, A.M., Bassendine, M.F. and Dali, A.K. (1999) Polymorphisms in GSTP1, GSTM1 and GSTT1 and Susceptibility to Colorectal Cancer. Cancer Epidemiology, Biomarkers \& Prevention, 8, 289-292.

[28] Steinhoff, C., Franke, K.H., Golka, K., et al. (2000) Glutathione Transferase Isozyme Genotypes in Patients with Prostate and Bladder Carcinoma. Archives of Toxicology, 74, 521-526. http://dx.doi.org/10.1007/s002040000161

[29] Ada, A.O., Suzen, S.H. and Iscan, M. (2004) Polymorphisms of Cytochrome P4501A1, Glutathione S-Transferases M1 and T1 in a Turkish Population. Toxicology Letters, 151, 311-315. http://dx.doi.org/10.1016/j.toxlet.2003.12.075

[30] Kiyohara, C., Yamamura, K., Nakanishi, Y., Takayama, K. and Hara, N. (2000) Polymorphism in GSTM1, GSTT1 and GSTP1 and Susceptibility to Lung Cancer in a Japanese Population. Asian Pacific Journal of Cancer Prevention, 1, 293-298.

[31] Millikan, R., Pittman, G., Tse, C.K., Savitz, D.A., Newman, B. and Bell, D. (2000) Glutathione Stransferases M1, T1, and P1 and Breast Cancer. Cancer Epidemiology, Biomarkers \& Prevention, 9, 567-573.

[32] Sctiawan, V.W., Zhang, Z.F., Yu, G.P., et al. (2000) GSTT1 and GSTM1 Null Genotypes and Risk of Gastric Cancer: A Case Control Study in a Chinese Population. Cancer Epidemiology, Biomarkers \& Prevention, 9, 73-80.

[33] Rossini, A., Rapozo, D.C.M., Amorim, L.M.F., et al. (2002) Frequencies of GSTM1, GSTT1, and GSTP1 Polymorphisms in a Brazilian Population. Genetics and Molecular Research, 1, 233-240.

[34] D’Alo, F., Voso, M.T., Guidi, F., et al. (2004) Polymorphisms of CYP1A1 and Glutathione S-Transferase and Susceptibility to Adult Acute Myeloid Leukemia. Haematologica, 89, 664-670.

[35] Gsur, A., Haidinger, G., Hinteregger, S., et al. (2001) Polymorphisms of Glutathione-S-Transferase Genes (GSTP1, GSTM1 and GSTT1) and Prostate Cancer Risk. International Journal of Cancer, 95, 152-155. http://dx.doi.org/10.1002/1097-0215(20010520)95:3<152::AID-IJC1026>3.0.CO;2-S

[36] Vettriselvi, V., Vijayalakshmi, K., Solomon Fd, P. and Venkatachalam, P. (2000) Genetic Variation of GSTM1, GSTT1 and GSTP1 Genes in a South Indian Population. Asian Pacific Journal of Cancer Prevention, 7, 325-328.

[37] Hamdy, S.I., Hiratsuka, M., Narahara, K., Endo, N., El-Enany, M., Moursi, N., Ahmed, M.S. and Mizugaki, M. (2003) Genotype and Allele Frequencies of TPMT, NAT2, GST, SULT1A1 and MDR-1 in the Egyptian Population. British Journal of Clinical Pharmacology, 55, 560-569. http://dx.doi.org/10.1046/j.1365-2125.2003.01786.x

[38] Duggan, C., Ballard-Barbash, R., Baumgartner, R.N., Baumgartner, K.B., Bernstein, L. and McTiernan, A.(2013) Associations between Null Mutations in GSTT1 and GSTM1, the GSTP1 Ile(105)Val Polymorphism, and Mortality in Breast Cancer Survivors. Springerplus, 11, 450.

[39] Wild, C.P., Yin, F., Turner, P.C., Chemin, I., Chapot, B., Mendy, M., Whittle, H., Kirk, G.D. and Hall, A.J. (2000) Environmental and Genetic Determinants of Aflatoxin-Albumin Adducts in the GAMBIA. International Journal of Cancer, 86, 1-7. http://dx.doi.org/10.1002/(SICI)1097-0215(20000401)86:1<1::AID-IJC1>3.0.CO;2-I 